\title{
Fertility Intentions of Childbearing-Age Migrant Women With One Child and Its Influences
}

\author{
Shilin $\mathrm{Ji}^{*}$ \\ School of Economics and Management, Beijing Jiaotong University, Beijing, China \\ ${ }^{*}$ Corresponding author. Email: j401997@163.com
}

\begin{abstract}
Rural-to-urban migrant women of childbearing-age with one child are the important research objects for studying China's two-child policy, the second child's willingness to give birth directly affects the supply and allocation of public health and family planning services in the inflow area. While the determining factors on fertility intentions of rural-to-urban migrant women remains understudied. We used the 2017 national monitoring survey data of the China Migrants Dynamic Survey (CMDS) for the analysis. Migrant women aged 20-49 with one child (24,767) from the CMDS 2017 were included in this study. Logistic regression was used to estimate the risk ratio (RR) and 95\% confidence intervals (CIs). The results showed that the logistic regression analysis showed fertility intentions in Chinese childbearing women was specifically related to 30-39 age group $(\mathrm{P}=0.004)$, in spring $(\mathrm{P}<0.0001)$ or in winter $(\mathrm{P}=0.006)$, small and medium-sized cities $(\mathrm{P}=0.044)$ and middle school education level $(\mathrm{P}=0.027)$.
\end{abstract}

Keywords: Fertility intentions, Second child, Migrant women with one child, China.

\section{INTRODUCTION}

With China's loosening of its long-standing onechild policy and the full implementation of the twochild policy, it has drawn much interest from both the academia and the public whether couples are actually willing to have a second child.

It is the fertility intentions that have an important part in reflecting the fertility concept, which was people's attitudes and views on fertility behavior based on life experiences.

Most of the previous studies limited to the fertility intentions for a second child among rural or urban women, which was a lack of studies among women migrants, especially among rural to urban women migrants. Rural-to-urban women migrants, who moved from rural to other places, makes up a large part of China's total population. According to the China Mobile Population Development Report 2017, the proportion of women in China's floating population has increased from 2011 to 2016, from $47.7 \%$ in 2011 to $48.3 \%$ in 2016. As a population group that is mostly of childbearing age, the intention and behavior of the second child will undoubtedly have an important impact on the level of the second child in China. Besides, due to the particularity of their identity, rural to urban women migrants are less affected by the restrictions on family planning policies, which would possibly keep the traditional concept of birth. There is a general preference for boys in the rural population who generally had the concept of adopted by children in old age. In the meantime, the factors restricting the fertility desire of the floating population are very complex, and age, education, household registration, fertility concept, child gender, etc. will affect fertility intentions, which caused a huge difference between urban women and women migrants.

Our finding aims to explore the factors that affect the fertility of migrants from the perspective of women migrants, which would expand the research ideas of previous studies. The study analyzed influencing factors of women migrants' fertility intention in China, predicting the fertility trends of migrant women in the next few years. Therefore, in the context of the comprehensive two-child policy, studying the fertility intention of this group and its influencing factors have great practical significance for raising the fertility level, which could be of great importance to alleviate the labor shortage and the aging of the population. Contribution of this article:First, in view of the important impact of fertility issues on the healthy development of China's economy and society and the inadequacy of existing 
research, our study used 2017 National Mobile Population Health and Family Planning Dynamic Monitoring Survey and reviews the above issues in detail, which is conducive to enriching China and other countries with similar situation to enrich their fertility research and guide fertility policy reforms. Compared with the existing literature, the marginal contribution of this paper is:

To the best of our knowledge, no research on this topic has taken place in China. Our study is an attempt to fill this gap and addresses the following three areas: Firstly, rural to urban women migrants was objective in our research, which broadens ideas in the present study. Secondly, RR (risk ratio) are applied to a prospective study, however, OR (odds ratio) are applied to a retrospective study. In the meantime, fertility intention for a second child is our object of study, which can be useful to forecast the fertility action of another child. Therefore, compared to using OR, it is with more persuasion to use RR in our study. Thirdly, our findings utilize whole country data which is comprehensive.

\section{METHODS}

\subsection{Study Design}

A cross-sectional survey of migrant women of childbearing-age with one child in China was conducted to collect information about intentions to have a second child and to explore factors that may be related to those intentions. All the participants were selected by using a stratified proportional random cluster sampling.

\subsection{Sample and Setting}

This study used the 2017 national monitoring survey data of the China Migrants Dynamic Survey (CMDS2017). This questionnaire mainly includes family members, income and expenditure, fertility intentions for a second child, employment situation, mobility and residence willingness, and health and public services, which is comprehensive. The percentage of the female population that aged between 18 and 49 years with one child is $51.91 \%$. Among migrant women of reproductive age, $51.91 \%$ of them had one child $(n=24767)$ were analyzed in this study. The target population in the present study was women migrants of childbearing age with one child. Inclusion criteria were as follows: (1) married women and aged between 18 and 49 years; (2) had only one child.

\subsection{Sample Size Determination}

The total number of women in the initial sample was 80912. After controlling women's age, domicile, and fertility status, the sample size decreased to 25446 . In addition, when selecting the appropriate variables, some missing values were eliminated, and the final sample size was 24767.

\subsection{Measurements}

The dependent variable was the participant's fertility intention for another child, measured by the question 'Do you intend to have a second child in the future?', with three answers 'Yes', "unsure" and 'No'.

The independent variables included socio-economic background factors. The socio-economic background factors included age, nationality, hukou type (government certificate of legal residency), highest educational level, marital status, received mind, flow range, district, age of the first child, gender of the first child and total income per month.

\subsection{Data Analysis}

The data were checked for errors before double entry into a computer. STATA, version 14.0, was used for data analysis, and a $<0.05$ was considered significant. Compared to using OR, it is with more persuasion to use RR in our study. Descriptive statistics, a chi-square test and a Log Binomial regression were applied to present the results. If more than $20 \%$ of the items had missing values, the questionnaire would be excluded as invalid.

\section{RESULTS}

\subsection{Sociodemographic Characteristics}

Table 1 reported the sociodemographic characteristics of the study participants. The average ages of the study participants were $34.20 \pm 6.8$ years (range: 18-49 years). Age groups were classified according to five different stages. More than half $(58.49 \%)$ of the participants were under the age of 35 years at the time of the study. $93 \%$ were Han ethnicity and only $7 \%$ were the minorities. Generally, the respondents were not highly educated, with only $36.23 \%$ having completed high school or received higher education, while $63.77 \%$ having a education level less than high school. $97.55 \%$ of the respondents were first marriage. Nearly four-fifths $(79.59 \%)$ of the participants received the concept of well-bear and wellrear. Regarding the geographical range of migration, nearly a quarter of them engaged in interprovincial migration $(23.1 \%)$, nearly half were intercity migrants $(49.76 \%)$, and $27.14 \%$ were intercounty migrants. 
Table 1. Sociodemographic characteristics of study participants $(\mathrm{n}=24767)$

\begin{tabular}{|c|c|c|}
\hline \multicolumn{3}{|l|}{ Characteristics } \\
\hline Age of women (years) & $\mathrm{N}$ & $\%$ \\
\hline$<25$ & 976 & 3.94 \\
\hline $25-29$ & 6,273 & 25.33 \\
\hline $30-34$ & 7,238 & 29.22 \\
\hline $35-39$ & 4,407 & 17.79 \\
\hline $40-49$ & 5,873 & 23.71 \\
\hline \multicolumn{3}{|l|}{ Ethnic group } \\
\hline Han & 23,033 & 93 \\
\hline Minority & 1,734 & 7 \\
\hline \multicolumn{3}{|l|}{ Highest education level } \\
\hline Less than high school & 15,795 & 63.77 \\
\hline high school and above & 8,972 & 36.23 \\
\hline \multicolumn{3}{|l|}{ Marital status } \\
\hline First marriage & 24,161 & 97.55 \\
\hline Remarry & 395 & 1.59 \\
\hline Live together & 211 & 0.85 \\
\hline \multicolumn{3}{|c|}{$\begin{array}{l}\text { whether received the concept } \\
\text { of well-bear and well-rear }\end{array}$} \\
\hline Yes & 19,713 & 79.59 \\
\hline No & 5,054 & 20.41 \\
\hline \multicolumn{3}{|l|}{ Scope of migration } \\
\hline Trans-provincial & 5,721 & 23.1 \\
\hline Cross-city within province & 12,324 & 49.76 \\
\hline Cross-county within the city & 6,722 & 27.14 \\
\hline \multicolumn{3}{|c|}{$\begin{array}{l}\text { Region of household } \\
\text { registration }\end{array}$} \\
\hline Western Region & 11,271 & 45.51 \\
\hline Central Region & 8,719 & 35.2 \\
\hline Eastern region & 4,777 & 19.29 \\
\hline \multicolumn{3}{|l|}{ Age of the first child (years) } \\
\hline$<4$ & 3,123 & 12.61 \\
\hline $4-5$ & 4,547 & 18.36 \\
\hline $6-9$ & 6,884 & 27.8 \\
\hline $10-12$ & 3,173 & 12.81 \\
\hline$>12$ & 7,040 & 28.42 \\
\hline \multicolumn{3}{|l|}{ Gender of the first child } \\
\hline Male & 15,191 & 61.34 \\
\hline Female & 9,576 & 38.66 \\
\hline \multicolumn{3}{|l|}{ Total income every month } \\
\hline$<5000$ & 6,756 & 27.28 \\
\hline $5000-7000$ & 10,258 & 41.42 \\
\hline$>7000$ & 7,753 & 31.3 \\
\hline
\end{tabular}

\subsection{Predicting Intentions to have a Second Child}

The concentration of fertility intention for a second child for all participants of different sub-groups was presented in Table 2. The results revealed that age of migrant women, ethnic group, highest education level, marital status, income, scope of migration, the age and gender of the first child were predictors of intentions to have a second child. It can be seen that with the age increasing, the proportion of migrant women who have intentions for a second child is gradually decreases from $39.04 \%$ to $4.99 \%$. Opposite trend was found in terms of education, respondents with higher education level revealed higher intentions $(27.80 \%)$ to have another child than other education groups. Minority were more likely to have a second child than ethnic Han. Migrant women who had received the concept of well-bear and well-rear $(25.40 \%)$ have higher odds of intending to have the next birth than those who had not received the education of well-bear and well-rear (19.57\%). In addition, the gender of the first child was significantly associated with second-child intentions. The intentions of having a second child for migrant women whose first child was a girl $(32.09 \%)$ were significantly higher than those whose first child was a boy $(19.25 \%)$.

More old respondents showed lower intentions to have a second child than younger respondents $(\mathrm{P}=0.000)$. National characteristics were significantly associated with second-child intentions $(\mathrm{P}=0.000)$. Respondents with higher education level revealed higher intentions to have more children than those with less than high school education level $(\mathrm{P}=0.000)$. Respondents who had received the concept of well-bear and well-rear showed higher intentions for a second child than those who had not received the education of well-bear and well-rear $(\mathrm{P}=0.000)$. The respondents showed higher intentions to have no more children as their domicile is located in the eastern region $(\mathrm{P}=0.000)$. Those whose first child was female reported higher intentions to dispose of no more children than those whose first child was male $(\mathrm{P}=0.000)$. The respondents showed lower intentions to have no more children at the age of the first child increased $(\mathrm{P}=0.000)$. Respondents who had higher total income per month showed higher intentions for a second child than those with lower income per month $(\mathrm{P}=0.000)$ (Table 2)

According to the analysis of the influencing factors of fertility intentions in the empirical literature and the purpose of this study, to more clearly express the relationship between the fertility willingness of migrant women and the characteristics of social demographics. Variables that had significant correlations with second child intentions by chi-square analysis were entered as independent variables in the log-binomial regression. We coded 0 as a response indicating 'not willing to or 
undecided to have a second child' and 1 as a response indicating 'willing to have a second child' to determine the predictors of participants' intentions to have another child.

Table 2. Distribution of fertility intention for a second child among study participants by sociodemographic variables ( $\mathrm{n}=24767)$

\begin{tabular}{|c|c|c|c|c|c|c|}
\hline \multirow{3}{*}{$\begin{array}{l}\text { Variables } \\
\text { Age of women (years) }\end{array}$} & & \multicolumn{4}{|c|}{ Intention for second childbirth } & \multirow[t]{3}{*}{$\mathrm{X}^{\wedge} 2(\mathrm{p})$} \\
\hline & \multirow[b]{2}{*}{$\mathrm{N}$} & \multicolumn{2}{|l|}{ NO } & \multicolumn{2}{|l|}{ YES } & \\
\hline & & $\mathrm{n}$ & $\%$ & $\mathrm{n}$ & $\%$ & \\
\hline$<25$ & 976 & 595 & 60.96 & 381 & 39.04 & $1.9 \mathrm{e}+03(0.000)$ \\
\hline $25-29$ & 6,273 & 4,085 & 65.12 & 2188 & 34.88 & \\
\hline $30-34$ & 7,238 & 5,034 & 69.55 & 2204 & 30.45 & \\
\hline $35-39$ & 4,407 & 3,476 & 78.87 & 931 & 21.13 & \\
\hline $40-49$ & 5,873 & 5,580 & 95.01 & 293 & 4.99 & \\
\hline \multicolumn{7}{|l|}{ Ethnic group } \\
\hline Ethnic Han & 23,033 & 17,581 & 76.33 & 5452 & 23.67 & $52.9151(0.000)$ \\
\hline Minority & 1,734 & 1,189 & 68.57 & 545 & 31.43 & \\
\hline \multicolumn{7}{|l|}{ Highest education level } \\
\hline Less than high school & 15,795 & 12,292 & 77.82 & 3503 & 22.18 & $98.4710(0.000)$ \\
\hline More than high school & 8,972 & 6,478 & 72.20 & 2494 & 27.80 & \\
\hline \multicolumn{7}{|l|}{ Marital status } \\
\hline First marriage & 24,161 & 18,313 & 75.80 & 5848 & 24.20 & $4.1056(0.128)$ \\
\hline Remarry & 395 & 308 & 77.97 & 87 & 22.03 & \\
\hline Live together & 211 & 149 & 70.62 & 62 & 29.38 & \\
\hline \multicolumn{7}{|l|}{ Received concept } \\
\hline Yes & 19,713 & 14,705 & 74.60 & 5008 & 25.40 & $74.6583(0.000)$ \\
\hline No & 5,054 & 4,065 & 80.43 & 989 & 19.57 & \\
\hline \multicolumn{7}{|l|}{ Scope of migration } \\
\hline Trans-provincial & 5,721 & 4,321 & 75.53 & 1400 & 24.47 & $87.2959(0.000)$ \\
\hline Cross-city within province & 12,324 & 9,613 & 78.00 & 2711 & 22.00 & \\
\hline Cross-county within the city & 6,722 & 4,836 & 71.94 & 1886 & 28.06 & \\
\hline \multicolumn{7}{|l|}{ District } \\
\hline Western Region & 11,271 & 8,634 & 76.60 & 2637 & 23.40 & $8.7508(0.013)$ \\
\hline Central Region & 8,719 & 6,522 & 74.80 & 2197 & 25.20 & \\
\hline Eastern region & 4,777 & 3,614 & 75.65 & 1163 & 24.35 & \\
\hline \multicolumn{7}{|l|}{ Age of the first child(years) } \\
\hline$<4$ & 3,123 & 2,195 & 70.28 & 928 & 29.72 & $1.6 \mathrm{e}+03(0.000)$ \\
\hline $4-5$ & 4,547 & 2,994 & 65.85 & 1553 & 34.15 & \\
\hline $6-9$ & 6,884 & 4,687 & 68.09 & 2197 & 31.91 & \\
\hline $10-12$ & 3,173 & 2,391 & 75.35 & 782 & 24.65 & \\
\hline$>12$ & 7,040 & 6,503 & 92.37 & 537 & 7.63 & \\
\hline \multicolumn{7}{|l|}{ Gender of the first child } \\
\hline Male & 15,191 & 12,267 & 80.75 & 2924 & 19.25 & $527.8837(0.000)$ \\
\hline Female & 9,576 & 6,503 & 67.91 & 3073 & 32.09 & \\
\hline \multicolumn{7}{|l|}{ Total income every month } \\
\hline$<5000$ & 6,756 & 5,189 & 76.81 & 1,567 & 23.19 & $43.0848(0.000)$ \\
\hline $5000-7000$ & 10,258 & 7,910 & 77.11 & 2,348 & 22.89 & \\
\hline$>7000$ & 7,753 & 5,671 & 73.15 & 2,082 & 26.85 & \\
\hline
\end{tabular}


The results showed that there was a statistically significant association between nationality, region, income level, hukou, the gender of the first child and received the concept of well-bear and well-rear $(\mathrm{P}<$ 0.05). Compared with migrant women aged 18-24, those who were 25 years of age or older had lower fertility intentions. $(\mathrm{RR}=0.88,95 \% \mathrm{CI}: 0.80$ to 0.95$)$; $(\mathrm{RR}$ $=0.77,95 \%$ CI: 0.70 to 0.84$)$; $(\mathrm{RR}=0.61,95 \%$ CI: 0.55 to 0.68$)$; $(\mathrm{RR}=0.18,95 \% \mathrm{CI}: 0.16$ to 0.22$)$. Minority were more likely to have a second child than ethnic Han $(\mathrm{RR}=1.19,95 \% \mathrm{CI}: 1.11$ to 1.28$)$. Participants who have received the education of well-bear and well-rear showed higher intentions to have a second child than those who have not participated $(\mathrm{RR}=0.85,95 \% \mathrm{CI}$ : 0.80 to 0.90$)$. The intentions of having a second child for migrant women whose first child was a girl were significantly higher than those whose first child was a boy $(\mathrm{RR}=1.48,95 \% \mathrm{CI}: 1.42$ to 1.55$)$. Family income and willingness to have a second child are U-shaped. Beyond a certain threshold, family income increases, and the willingness to have a second child will also increase. Women migrants whose first child's age showed lower intentions to have another child (RR $=1.19,95 \% \mathrm{CI}: 1.11$ to 1.27$) ;(\mathrm{RR}=1.23,95 \% \mathrm{CI}: 1.15$ to 1.32$)$; $(\mathrm{RR}=1.16,95 \% \mathrm{CI}: 1.06$ to 1.27$)$; $(\mathrm{RR}=0.78$, 95\% CI: 0.69 to 0.89$)$. Women migrants who had lower income had lower fertility intention than those who had larger income $(\mathrm{RR}=0.97,95 \% \mathrm{CI}$ : 0.92 to 1.03$)$; $(\mathrm{RR}$ $=1.10,95 \% \mathrm{CI}: 1.04$ to 1.16 ). Participants who have received more than high school education showed lower intentions to have a second child than those who have less than high school education $(\mathrm{RR}=0.95,95 \% \mathrm{CI}$ : 0.91 to 1.00 )

\section{DISCUSSION}

With the implementation of the comprehensive twochild policy, the reproductive behavior of large-scale migrant women of childbearing age is likely to have an impact on urban health and family planning services. China's migrant population is large, and there is a trend of further growth in the future. The fertility intentions of migrant women, to some extent, aggravate the complexity of the family planning service, which will have a profound impact on future marriage and fertility level and family structure.
Table 3. Log-binomial regression analysis of factors influencing second-child intention

\begin{tabular}{|c|c|c|c|}
\hline Variable & $\mathrm{RR}$ & $\mathrm{P}>|\mathrm{z}|$ & $95 \% \mathrm{CI}$ \\
\hline \multicolumn{4}{|l|}{ Age of women } \\
\hline $25-29$ & 0.8753 & 0.0020 & $\begin{array}{l}0.80- \\
0.95\end{array}$ \\
\hline $30-34$ & 0.7669 & 0.0000 & $\begin{array}{l}0.70- \\
0.84\end{array}$ \\
\hline $35-39$ & 0.6107 & 0.0000 & $\begin{array}{c}0.55- \\
0.68\end{array}$ \\
\hline $\begin{array}{c}40-49 \\
<25\end{array}$ & $\begin{array}{c}0.1849 \\
1.0000 \\
\text { (Reference) }\end{array}$ & 0.0000 & $\begin{array}{c}0.16- \\
0.22\end{array}$ \\
\hline $\begin{array}{l}\text { Nationality } \\
\text { Minority }\end{array}$ & 1.1941 & 0.0000 & $\begin{array}{l}1.11- \\
1.28\end{array}$ \\
\hline Ethnic Han & $\begin{array}{c}1.0000 \\
\text { (Reference) }\end{array}$ & & \\
\hline \multicolumn{4}{|l|}{ Income } \\
\hline $5000-7000$ & 0.9743 & 0.3350 & $\begin{array}{c}0.92- \\
1.03 \\
\end{array}$ \\
\hline $\begin{array}{l}>7000 \\
<5000\end{array}$ & $\begin{array}{c}1.1007 \\
1.0000 \\
\text { (Reference) }\end{array}$ & 0.0010 & $\begin{array}{l}1.04- \\
1.16\end{array}$ \\
\hline $\begin{array}{l}\text { Highest education level } \\
\text { More than high school } \\
\text { Less than high school }\end{array}$ & $\begin{array}{c}0.9530 \\
1.0000 \\
\text { (Reference) }\end{array}$ & 0.0340 & $\begin{array}{l}0.91- \\
1.00\end{array}$ \\
\hline $\begin{array}{l}\text { Whether received the concept } \\
\text { of well-bear and well-rear } \\
\text { Yes } \\
\text { No }\end{array}$ & $\begin{array}{c}0.8464 \\
1.0000 \\
\text { (Reference) }\end{array}$ & 0.0000 & $\begin{array}{c}0.80- \\
0.90\end{array}$ \\
\hline \multicolumn{4}{|l|}{ Age of the first child(years) } \\
\hline $4-5$ & 1.1854 & 0.0000 & $\begin{array}{l}1.11- \\
1.27 \\
\end{array}$ \\
\hline $6-9$ & 1.2313 & 0.0000 & $\begin{array}{l}1.15- \\
1.32 \\
\end{array}$ \\
\hline $10-12$ & 1.1619 & 0.0010 & $\begin{array}{l}1.06- \\
1.27\end{array}$ \\
\hline $\begin{array}{l}>12 \\
<4\end{array}$ & $\begin{array}{c}0.7828 \\
1.0000 \\
\text { (Reference) } \\
\end{array}$ & 0.0000 & $\begin{array}{c}0.69- \\
0.89\end{array}$ \\
\hline $\begin{array}{l}\text { Gender of child } \\
\text { Female } \\
\text { Male }\end{array}$ & $\begin{array}{c}1.4837 \\
1.0000 \\
\text { (Reference) } \\
\end{array}$ & 0.0000 & $\begin{array}{l}1.42- \\
1.55\end{array}$ \\
\hline cons & 0.3404 & 0.0000 & $\begin{array}{l}0.30- \\
0.38\end{array}$ \\
\hline
\end{tabular}


In general, the fertility intentions of migrant women tend to be different from those of their rural or urban counterparts, which are influential in their future childbearing. Our findings revealed low fertility intentions among rural to urban women migrants with one child after the implementation of China's universal two-child policy. Among the female population who currently have a child, only less than $30 \%$ indicated that they intend to have two children, and the actual fertility will be relatively low, to a certain degree, which was seriously affected by the long-term implementation of the "one-child" birth policy.

Low fertility intentions among our target population could have been influenced by some of the participants' characteristics. Compared with women in the urban population, rural to urban women migrants have generally lower levels of education and lower incomes and strong boy preferences, which could partly account for their high fertility intentions. Nearly half of women migrants are in the eastern region, to a certain degree, which would make it possible to be affected by the urban environment.

Firstly, under the factors of controlling nationality, district, income level, education level, the gender of the child, etc., with the gradual increase of age, the fertility intention of migrant women will gradually weaken. There is a difference in age of fertility intention, and the older the woman, the lower the intention to have another child. Studies have shown that women's best reproductive age is 23 to 30 years old. Our finding indicated that more than $70 \%$ of the female migrant population is older than 30 years old, which is also an influencing factor of low fertility intention from a physiological point of view.

Similar trend was also found in terms of education, with the education level increased, fertility intentions of migrant women was gradually reduced. This might because people with higher level of education had stronger awareness of improving quality of child, resulting in a lower demand for the number of children. The improvement of women's education will also increase their human capital level, which will increase the value of time and fertility cost and reduce the willing fertility rate. In addition, the level of education, especially for migrant women, can reduce fertility intentions through changing traditional fertility concepts and delaying the age of marriage and childbirth.

Secondly, nationality could also play an important role in decisions regarding childbearing. The floating population of minorities has a higher fertility intention than ethnic Han; the probability of rural migrants not planning to have another child is significantly lower than that of urban households. It can be said that rural residents in China prefer more children compared with their urban counterparts and this traditional cultural influence remains with those migrants of rural origin even after they have moved to cities. The data also demonstrated that among urban women who currently have one child, the proportion of children who have fewer intentions to have two children is higher. The main reason is that the expense of raising the child is higher. Nowadays, there is an increasing trend that parents play an important role in the cultivation of children's quality, and the child's birth and parenting costs continue to rise. At the same time, as urban housing prices continue to rise, the youth groups at the peak of childbearing face enormous pressure on home purchases. Therefore, for women migrants, their status is not very stable and the burden is heavier.

In the meantime, economic strength is a realistic objective factor related to fertility intentions. Studies have found the income level has a significant impact on the fertility desire of residents to have another child. It is shown in the data that family economic conditions were permitted and a second child is planned. Therefore, households with higher incomes are more likely to have a two-child birth plan.

Among the factors that influence the birth of second child, son preference is also a factor that cannot be ignored. The influence of son preference remains strong among migrant women, whose first child was a girl had significantly higher odds of progressing to the next birth than those whose first child was a boy. We can say that although the concept of gender equality has been popularized with the development of society, the traditional concept of son preference still remains strong among those migrants of rural origin even after they have moved to cities and influence on future fertility intentions and motivated them to have more children and expect to give birth to at least one boy. On the contrary, if the first child is a boy, and fear that regenerating a boy will increase the family's economic pressure, the fertility will be reduced. Previous studies confirmed the negative effect of son preference that is consistent with our findings. Quanbao Jiang et al. indicated a strong preference for sons played an important role in decreasing the probability of having a second child. (Quanbao Jiang, Ph.D., Ying Li, Ph.D. candidate, and Jesús J. Sanchez-Barricarte, Ph.D.) Studies had also confirmed that sex-selective abortion would decrease children's number and subsequently the fertility level in China which is consistent with our study. Also, women who have received the concept of well-bear and well-rear have higher requirements for the quality of their children's parenting, and the fertility of the second child is more cautious. Therefore, the fertility intention of the second child would decline.

This study also inevitably has certain limitations. First, the cross-sectional data is used in this study. The causal relationship between the independent variable and the dependent variable cannot be determined in the cross-section data. Besides, our study did not use 
comparative analysis, such as male opinion on the birth of two children, which made our study relatively single.

\section{CONCLUSION}

It is unsure that the universal two-child policy will be enough to prompt an increase in fertility among rural to urban women migrants with one child in China. Although the adjustment of fertility policy can release certain fertility potential, it is difficult to change the fertility intentions fundamentally, the overall intentions for a second child among women migrants with one child are low in China. Fertility intentions are complex, and fertility intentions for a second child are not affected by policies only; other factors also play an important role. Childcare support policies and family support are urgently needed to create a better environment for childbearing in China. Supplementary measures such as strengthening the provision of public services, reducing the cost of child-rearing, and introducing childcare support policies and family support are urgently needed to create a favorable environment for childbearing in China.

\section{REFERENCES}

[1] VOGL T S.Differential fertility, human capital, and development [J]. The Review of Economic Studies, 2015, 83 (1): 365 - 401.

[2] Feng W, Cai Y, Gu B. Population, policy, and politics: how will history judge China's one-child policy? Popul Dev Rev 2013; 38:115e29.

[3] Zeng Y, Hesketh T. The effects of China's universal two-child policy. The Lancet 2016; 388:1930e8.

[4] Machiyama K, Mumah JN, Mutua M, Cleland J. Childbearing desires and behaviour: a prospective assessment in Nairobi slums. BMC Pregnancy Childbirth 2019;19.

[5] Kuhnt A-K, Trappe H. Channels of social influence on the realization of short-term fertility intentions in Germany. Adv Life Course Res 2016; 27:16e29.

[6] Zheng Y, Yuan J, Xu T, Chen M, Liang H, Connor $\mathrm{D}$, et al. Socioeconomic status and fertility intentions among Chinese women with one child. Hum Fertil 2016; 19:43e7.

[7] Bao L, Chen F, Zheng Z. Transition in second birth intention in a low fertility context: the case of Jiangsu, China. Asian Popul Stud 2017;13(2):198e222.

[8] Ye B, Zhao Y. Women hold up half the sky? Gender identity and the wife's labor market performance in China. China Econ Rev 2018; 47:116e41.

[9] Liang J, Mu Y, Li X, Tang W, Wang Y, Liu Z, et al. Relaxation of the one child policy and trends in caesarean section rates and birth outcomes in China between 2012 and 2016: observational study of nearly seven million health facility births. BMJ 2018.

[10] Shi Y, Jiang Y, Zeng Q, Yuan Y, Yin H, Chang C, et al. Influencing factors associated with the mode of birth among childbearing women in Hunan Province: a cross-sectional study in China. BMC Pregnancy Childbirth 2016;16(1):108.

[11] Aassve A, Billari FC, Pessin L. Trust and fertility dynamics. So Forces 2016; 95:663e92.

[12] Gong SY, Wang H, Liu DM. Analysis on prenatal care utilization among married migrant women Maternal and Child Health Care of China. 2017,32(10):2187-2189.

[13] Hodgson S, Lurz PW, Shirley MD, Bythell M, Rankin J. Exposure misclassification due to residential mobility during pregnancy. Int $\mathrm{J}$ Hyg Environ Health. 2015; 218: 414-21.

[14] Akinola AB, Krishna AK, Chetlapalli SK. Health equity for internal migrant labourers in India: an ethical perspective. Indian J Med Ethics. 2014; 11(4):232-7.

[15] Mirkuzie AH. Exploring inequities in skilled care at birth among migrant population in a metropolitan city Addis Ababa, Ethiopia; a qualitative study. Int $\mathrm{J}$ Equity Health. 2014; 13:110.

[16] ICF International. The Demographic and Health Surveys. http://dhsprogram.com/. Accessed 12 January 2015.

[17] Schoumaker B. Quality and Consistency of DHS Fertility Estimates, 1990 to 2012. Methodological Reports No. 12. Rockville, Maryland: ICF International, DHS; 2014.

[18] S. Lee, A.-Z. Duvander, S.H. Zarit How can family policies reconcile fertility and women's employment? Comparisons between South Korea and Sweden Asian J Wom Stud, 22 (2016), pp. 269-288

[19] Y. Shi, Y. Jiang, Q. Zeng, Y. Yuan, H. Yin, C. Chang, et al.Influencing factors associated with the mode of birth among childbearing women in Hunan Province: a cross-sectional study in China BMC Pregnancy Childbirth, 16 (1) (2016), p. 108 
[20] J. Liang, Y. Mu, X. Li, W. Tang, Y. Wang, Z. Liu, et al. Relaxation of the one child policy and trends in caesarean section rates and birth outcomes in China between 2012 and 2016: observational study of nearly seven million health facility births BMJ (2018) 